\title{
Disclosures of Huntington Disease Risk Within Families: Patterns of Decision-Making and Implications
}

\author{
Robert Klitzman, ${ }^{1 *}$ Deborah Thorne, ${ }^{2}$ Jennifer Williamson, ${ }^{3}$ Wendy Chung, ${ }^{4}$ and Karen Marder ${ }^{5}$ \\ ${ }^{1}$ Associate Professor of Clinical Psychiatry, College of Physicians and Surgeons and Mailman School of Public Health, \\ Columbia University, New York, New York \\ ${ }^{2}$ Department of Neurology, Psychiatry, College of Physicians and Surgeons, Columbia University, New York, New York \\ ${ }^{3}$ Department of Neurology, Psychiatry, College of Physicians and Surgeons, Gertrude H. Sergievsky Center, \\ Columbia University, New York, New York \\ ${ }^{4}$ Departments of Pediatrics and Medicine, College of Physicians and Surgeons, Columbia University, New York, New York \\ ${ }^{5}$ Department of Neurology, Psychiatry, College of Physicians and Surgeons, Gertrude H. Sergievsky Center, \\ Taub Instititue for Alzheimer's Disease and the Aging Brain, Columbia University, New York, New York
}

Received 14 April 2006; Accepted 19 April 2007

Patterns of disclosure of Huntington disease risk and genetic test results among family members are important, but have been underexplored. We interviewed 21 individuals indepth-eight mutation-positive for HD, four mutationnegative, and nine not tested-for $2 \mathrm{hr}$ each. Within families, critical questions arose of what, when, and to whom to disclose, and what to do post-disclosure. Interviewees wrestled with dilemmas of what to tell (e.g., suspicions vs. confirmed symptoms; initiation vs. completion of testing; partial vs. indirect information), how to disclose (e.g., planning in advance vs. "blurting out" information in arguments), and whether and how to tell extended family members. Questions arose of when to tell (i.e., to avoid disclosing "too early" or "too late"). Similarities and differences emerged related to types of relationships (e.g., parents telling offspring vs. offspring telling parents vs. siblings telling each other). Individuals often disclosed because of perceived duty to foster the health of their family members, enabling these others to pursue appropriate medical evaluation, if desired. Yet tensions arose because the information could burden these members, who also have rights to remain "in denial" if they wish and not discuss the topic or pursue testing. Post-disclosure, dilemmas emerged of whether and how much to encourage family members to pursue testing. These data shed important light on critical issues that have received little, if any, attention concerning what, how, and when disclosure occurs, and have key implications for at-risk individuals, genetic counselors, and other health care workers (HCWs), and for future research. At-risk individuals would benefit from considering these issues in advance. HCWs need to realize that these decisions are multi-faceted. Future research can explore whether, when, how, and how often HCWs raise these issues with individuals. (c) 2007 Wiley-Liss, Inc.

Key words: Huntington disease; genetics; disclosure; families; secrets; privacy/confidentiality; stigma; ethics; decision-making; genetic discrimination; children; kinship

\section{How to cite this article: Klitzman R, Thorne D, Williamson J, Chung W, Marder K. 2007. Disclosures of Huntington disease risk within families: Patterns of decision-making and implications. Am J Med Genet Part A 143A:1835-1849.}

\section{INTRODUCTION}

Patterns of disclosures of Huntington disease (HD) risk and test results among family members are important, but remain underexplored. HD testing, once disclosed, can affect families in many ways [Sobel and Cowan, 2000], but how do individuals make decisions concerning disclosure of this information? In general, individuals do not always communicate genetic risks to all family members [Sorenson et al., 2003]. Yet only a few studies have begun to probe these areas with regard to HD. Research on disclosures of HD and other genetic disorders has also tended to focus on whether and why, but not what, how, and when disclosure occurs.

Forrest et al. [2003] found that in Northeast Scotland, disclosures of risk for hereditary breast and ovarian cancer (HBOC) and/or HD created

Grant sponsor: National Human Genome Research Institute; Grant number: 5-R01-HG002431-01.

*Correspondence to: Robert Klitzman, M.D., HIV Center, Unit 15, 1051 Riverside Drive, New York, NY 10032. E-mail: rlk2@columbia.edu

DOI 10.1002/ajmg.a.31864 
problems for mutation-positive individuals. In these decisions, pre-existing cultural and familial factors were important-particularly, relationships in families, and "hierarchies and authority structures seen in the 'British' kinship system" (which emphasizes "vertical" rather than "horizontal" relations) [Forrest et al., 2003]. Disclosure was seen as a process rather than an "act;" and two styles were described, of "pragmatism" and "prevarication"-disclosing proactively versus looking for "the right moment." Yet differences may exist in a U.S. setting. In a second, qualitative study, Hamilton et al. [2005] interviewed 29 individuals-10 who tested for HD, 2 untested at-risk, and 17 tested or at-risk for HBOC, and described three processes involved in disclosure decisions. Participants considered family members' vulnerability versus receptivity; selected what and to whom to disclose different aspects of information; and based timing on the readiness of both the teller and receiver of the information. Most participants did not disclose more than the fact of the HD test result itself, unless asked.

Yet research on other genetic diseases has demonstrated that disclosure is very complex, and that numerous barriers exist [Green et al., 1997; Forrest Keenan et al., 2005]. In general, families are complicated interactive social units, varying in norms [Sorenson and Wertz, 1986; Sorenson et al., 2003]. Most individuals prefer to have disclosures of genetic information to family members done by themselves rather than by health care workers (HCWs) [Lerman et al., 1998]. Yet genetic information is selectively communicated [Sorenson et al., 2003]. Though individuals may disclose to family members the presence of treatable hereditary nonpolyposis colon cancer (HNPCC) [Peterson et al., 2003], a significant portion of patients with balanced chromosomal abnormalities do not inform all their at-risk relatives [Suslak et al., 1985; Ayme et al., 1993]. Numerous obstacles impede communication about breast cancer [Julian-Reynier et al., 2000], and cystic fibrosis testing [Fanos and Johnson, 1995]. Overall, whether disclosure occurs may be associated less with disease-related factors than with individual, familial, and socio-cultural factors [Wilson et al., 2004]. With breast cancer, disclosure may increase with age, having had cancer [Julian-Reynier et al., 2000], being a mother, having higher distress [Tercyak et al., 2001], older children, and more open parent-adolescent communication [Tercyak et al., 2002], being a carrier [Lerman et al., 1998; Hughes et al., 2002], and seeking support and medical advice [Lerman et al., 1998; Hughes et al., 2002]. Particular obstacles may hamper disclosure of genetic HNPCC risks to extended family members [Peterson, 2005]. With cystic fibrosis, patients often do not want HCWs to contact relatives with information [Sorenson et al., 1996], and relatives are often not interested in free education or counseling about this disease [Sorenson et al.,
1997]. But HD differs from these other genetic disorders in critical ways. Plantinga et al. [2003] explored disclosure among individuals with four genetic versus four non-genetic conditions, but did not include HD. These two groups generally did not differ-for example, both groups objected to a doctor disclosing information without their knowledge to other family members [Plantinga et al., 2003]. Yet the conditions explored were heterogeneousfor example, HIV was examined as a non-genetic disease, though it evokes strong privacy concerns that may make it similar to certain genetic more than non-genetic diseases.

In contrast, research on disclosures of HIV has found that individuals vary in what, how, and when they disclose (e.g., disclosing indirectly or in "code"). Disclosures of this other stigmatized disease can be fraught with guilt [Klitzman, 1997; Klitzman and Bayer, 2003].

But most research on genetic disclosure has examined whether, but not what, how, and when disclosures occur. With HD as well, disclosures may be affected by guilt, fear, shame, or discomfort. Yet how individuals at risk for HD experience, view, and approach these issues, and how these factors affect disclosure decisions have been under-explored. In contrast to many other disorders, HD invariably affects other family members. Disclosures may also have psychological implications that can in turn shape subsequent health decisions. With breast cancer, obtaining test results can profoundly affect family members [Dudok DeWit et al., 1994], and psychological distress may decrease with disclosure to sisters, while increasing with disclosure to young children [Lerman et al., 1998].

According to the Health Belief Model, an individual's health behavior is shaped by perceived susceptibility, disease severity, and costs and benefits of the behavior [Rosenstock et al., 1988]. Such a model may apply to decisions about HD disclosures and testing decisions, but has not been examined in these contexts. Individuals often learn that they are at risk for HD when they have been informed by family members who are themselves at risk, mutationpositive, or symptomatic. Thus, whether, when, how, and to whom an individual discloses HD information within a family may shape whether, when, and how these members make decisions about whether to pursue testing or have children. How information is disclosed can also affect whether and how one in turn eventually discloses it to others.

Recent policy changes may also mold these issues. The Health Insurance Portability and Accountability Act (HIPAA) protects health information generally. Many states have enacted genetic privacy laws, but these differ, and no federal genetic privacy law currently exists [NCSL, 2006]. State laws remain untested in courts, and debates exist about the merits of "genetic exceptionalism"-treating genetic and 
other medical information as distinct [Everett, 2004]. Nevertheless, physicians may feel important ethical duties to disclose genetic test results to patients' family members, if such information can prevent harm, and would not otherwise be disclosed [Deftos, 1998].

Critical aspects of meaning and stigma may shape HD disclosure decisions. Individuals "at risk" for breast cancer experience this state subjectively as "somewhere between health and illness," "a condition of non-health" [Gifford, 1986]. Goffman [1963] has described how individuals with stigmatized conditions struggle and seek to "manage" such information, and "pass," though such management can be hard. But with HD, individuals manage information for others, too, that is about these others. Parsons has also described the "sick role" as entailing rights and responsibilities, exemptions from certain duties, and obligations to get well [Parsons, 1951]. Individuals at-risk for HD must choose, through disclosure decisions, whether to put others and themselves into the role of being seen as "at risk," and what that means. On theoretical grounds, too, Geertz [1973] has advocated studying aspects of individuals' lives and social situations not by imposing theoretical structures, but from trying to understand individuals' own experiences, drawing on their own words and perspectives to obtain a "thick description".

These issues are increasingly important, as on-line websites are helping individuals to connect distant relatives and construct genealogies (e.g., www. ancestry.com), leading to disclosures of previously unknown risks of HD and other genetic disorders. Such on-line services can potentially facilitate matches for tissue donations, but can lead to awareness of hitherto unexpected genetic risks that may not be optimally disclosed. Internet sites also offer testing for other genetic disorders (though not HD). In short, many critical questions remain concerning how individuals who have or are at risk for HD make these complex disclosure decisions, and what factors are involved.

\section{MATERIALS AND METHODS}

To understand most fully the range of factors that may be involved, we used qualitative methods and, as summarized in Table I, interviewed in-depth 21 individuals - eight mutation-positive for HD, four mutation-negative, and nine not tested-for $2 \mathrm{hr}$ each.

Potential participants were approached by staff at an HD clinic. Attempts were made to ask all people who underwent pre-symptomatic testing and a range of others if they would participate. With each participant, the principal investigator (PI) of this project conducted a $2 \mathrm{hr}$ in-depth semi-structured interview concerning experiences of being at risk for $\mathrm{HD}$ and undergoing the process of testing, and/or learning one's genetic status. Interviews were conducted at participants' offices or homes or in the

TABLE I. Summary of Characteristics of Sample

\begin{tabular}{|c|c|c|c|c|c|c|c|c|c|c|}
\hline $\begin{array}{l}\text { Subject } \\
\text { ID }\end{array}$ & Sex & Race & $\begin{array}{l}\text { Symptom } \\
\text { status }\end{array}$ & $\begin{array}{l}\text { Test } \\
\text { status }\end{array}$ & $\begin{array}{l}\text { Highest level of } \\
\text { education }\end{array}$ & Profession & $\begin{array}{l}\text { Marital } \\
\text { status }\end{array}$ & \# of children & $\begin{array}{l}\text { Years } \\
\text { since } \\
\text { testing }\end{array}$ & $\begin{array}{c}\text { Years } \\
\text { since } \\
\text { diagnosis }\end{array}$ \\
\hline 1 & $\mathrm{~F}$ & W & $\mathrm{Sx}$ & NT & HS & Housewife & M & 3 & $\mathrm{n} / \mathrm{a}$ & 1 \\
\hline 2 & $\mathrm{M}$ & B & Sx & NT & 4 years college & Professional & M & 0 & $\mathrm{n} / \mathrm{a}$ & 2 \\
\hline 3 & $\mathrm{M}$ & W & Asx & NT & 4 years college & Professional & $\mathrm{S}$ & 0 & $\mathrm{n} / \mathrm{a}$ & $\mathrm{n} / \mathrm{a}$ \\
\hline 4 & M & W & Asx & + & Some graduate & Professional & $\mathrm{S}$ & 0 & 2 & $\mathrm{n} / \mathrm{a}$ \\
\hline 5 & M & W & Asx & + & $<4$ years college & Professional & $\mathrm{S}$ & 0 & 2 & $\mathrm{n} / \mathrm{a}$ \\
\hline 6 & M & W & Sx & + & Some graduate & Unemployed & $S$ & 0 & & \\
\hline 7 & $\mathrm{~F}$ & W & Asx & + & 4 years college & Professional & M & 2 & 1 & $\mathrm{n} / \mathrm{a}$ \\
\hline 8 & $\mathrm{~F}$ & W & Asx & NT & HS & Blue collar & $\mathrm{M}$ & 3 & $\mathrm{n} / \mathrm{a}$ & $\mathrm{n} / \mathrm{a}$ \\
\hline 9 & $\mathrm{~F}$ & W & Asx & NT & $<4$ years college & White collar & $\mathrm{M}$ & 1 & $<1$ & $\mathrm{n} / \mathrm{a}$ \\
\hline 10 & $\mathrm{~F}$ & $\mathrm{~B}$ & Asx & NT & HS & Unemployed & $\mathrm{S}$ & 0 & $\mathrm{n} / \mathrm{a}$ & $\mathrm{n} / \mathrm{a}$ \\
\hline 11 & M & W & Asx & - & Some graduate & Professional & M & $\begin{array}{l}0 \text { ( } 1 \text { child } \\
\text { post-testing) }\end{array}$ & 1 & $\mathrm{n} / \mathrm{a}$ \\
\hline 12 & $\mathrm{~F}$ & W & Asx & - & Some graduate & Professional & $\mathrm{M}$ & 1 & 1 & $\mathrm{n} / \mathrm{a}$ \\
\hline 13 & M & W & Asx & - & $<\mathrm{HS}$ & Professional & M & 2 & 3 & $\mathrm{n} / \mathrm{a}$ \\
\hline 14 & M & W & Asx & + & 4 years college & Blue collar & M & 3 & 1 & $\mathrm{n} / \mathrm{a}$ \\
\hline 15 & $\mathrm{M}$ & W & Sx & + & Some graduate & Student & M & 0 & 6 & 1 \\
\hline 16 & $\mathrm{~F}$ & W & Asx & NT & 4 years college & Professional & $\mathrm{D}$ & 0 & $\mathrm{n} / \mathrm{a}$ & $\mathrm{n} / \mathrm{a}$ \\
\hline 17 & $\mathrm{M}$ & $\mathrm{L}$ & Asx & NT & 4 years college & Unemployed & $\mathrm{S}$ & 0 & $\mathrm{n} / \mathrm{a}$ & $\mathrm{n} / \mathrm{a}$ \\
\hline 18 & $\mathrm{M}$ & W & Sx & + & 4 years college & Unemployed & $\mathrm{S}$ & 0 & $<1$ & $<1$ \\
\hline 19 & $\mathrm{~F}$ & W & Sx & NT & 4 years college & Blue collar & $\mathrm{S}$ & 0 & $\mathrm{n} / \mathrm{a}$ & 5 \\
\hline 20 & M & W & $\mathrm{Sx}$ & + & Some graduate & $\begin{array}{l}\text { Unemployed, } \\
\text { former professional }\end{array}$ & M & 1 & 2 & 2 \\
\hline 21 & $\mathrm{~F}$ & W & Asx & - & Some graduate & Professional & $\mathrm{S}$ & 0 & 6 & $\mathrm{n} / \mathrm{a}$ \\
\hline
\end{tabular}

Race: B, black; W, white; L, latino/a. Symptom status: Asx, asymptomatic; Sx, symptomatic. Test status: NT, not tested; +, positive test result; -, negative test result. Level of education: HS, high school. Some graduate includes those who did and did not complete degrees. Marital status: M, married; S, single; D, divorced. 
TABLE II. Sample Questions From Semi-Structured Interview Guide

When did you learn that you were at risk of HD and what was your reaction to it at that time?

Have you had genetic testing done? If so, what was the result and how did you respond?

Have you ever felt stigma or discrimination because of HD?

Have you been concerned about threats to privacy? How so?

Whom have you told or not told about your risk for HD?

Have you told family members (spouse/significant other; sisters; brothers; parents; children; other extended family members; in-laws)? Health care professionals (primary physician or other physician in different contexts) or others?

In each case, what, when, and why did you disclose?

How have you made these decisions?

Have you ever disclosed to someone who then told others? Has your health information ever "leaked out" or led to discrimination, and, if so, how?

Do you have any other thoughts about these issues?

PI's office-whichever was more convenient for participants. The Columbia University Department of Psychiatry Institutional Review Board approved the study. Relevant sections of the interview guide are attached (See Table II), through which we sought to obtain detailed descriptions of the above issues [Geertz, 1973]. Transcriptions and analyses of interviews occurred during the period in which the interviews were being conducted. Interviews were conducted until major and minor themes became clear.

Interviews were analyzed, informed by grounded theory [Strauss and Corbin, 1990]. Grounded theory involves both deductive and inductive thinking, building inductively from the data to an understanding of themes and patterns within the data, and deductively, drawing on frameworks from prior research and theories. Once the full set of interviews was conducted, analyses were conducted in two phases, primarily by the PI together with a research assistant (RA) who had social science training. At several points during the coding process, we also received input from an additional, senior expert in qualitative research.

The PI and the RA independently examined a subset of interviews to assess factors that shaped participants' experiences, identifying categories of recurrent themes and issues that were subsequently given codes. The coders assessed similarities and differences between participants, examining categories that emerged, ranges of variation within categories, and variables that may be involved. The coders developed a coding manual and examined areas of disagreement until reaching consensus between them. New themes that did not fit into the original coding framework were discussed, and modifications were made in the manual when deemed appropriate. In phase 2 of the analysis, we refined and merged subdivided thematic categories into secondary or sub-codes, when suggested by associations, or overlap in the data. Codes and subcodes were then used in analysis of all of the interviews. To ensure coding reliability, two coders analyzed all interviews. Again, we examined areas of disagreement until consensus was reached. Major codes included for example telling children and telling parents. Sub-codes (or sub-themes) included specific reasons to tell or not (e.g., telling to receive support, or not telling in order to avoid burdening parents). We conducted thematic content analyses, and to ensure rigor and trustworthiness of the data, we used two coders and an outside consultant, and triangulated coding categories and methods, referring to the published literature, as described above. Moreover, our findings appear to have a certain face validity. The New York State Psychiatric Institute IRB approved this study and all participants gave informed consent.

\section{RESULTS}

Critical themes arose in families, with each disclosure decision involving key questions of what, how, when, why, and whom to tell. Overall, these themes suggest a framework or model as illustrated in Figure 1. In general, what, how, why, and when disclosure occurred was shaped by who was told. Reasons to disclose or not were shaped by the type of relationship (i.e., telling a parent vs. siblings vs. an older or younger child). Below, these domains are organized and presented separately and sequentially to provide a sense of each. Yet clearly, these categories are closely inter-related. Following disclosure, questions emerged concerning whether and to what degree to encourage offspring and other family members to pursue testing themselves.

\section{What to Tell}

Individuals struggled with questions of what to tell, and disclosed a range of information-for example, that they suspected that they might have either symptoms or the mutation, have initiated genetic counseling, or have gotten test results.

At one extreme, a few disclosed nothing to certain family members (e.g., "I've told nobody except my husband-not my siblings" [7:F/Asx/+]) But such non-disclosers tended to be asymptomatic. Other individuals made more fine-grained disclosure decisions.

They had to decide, for example, whether to tell that they merely suspected symptoms (e.g., "if I have a little sort of twitch in my hand: is that the sort of 


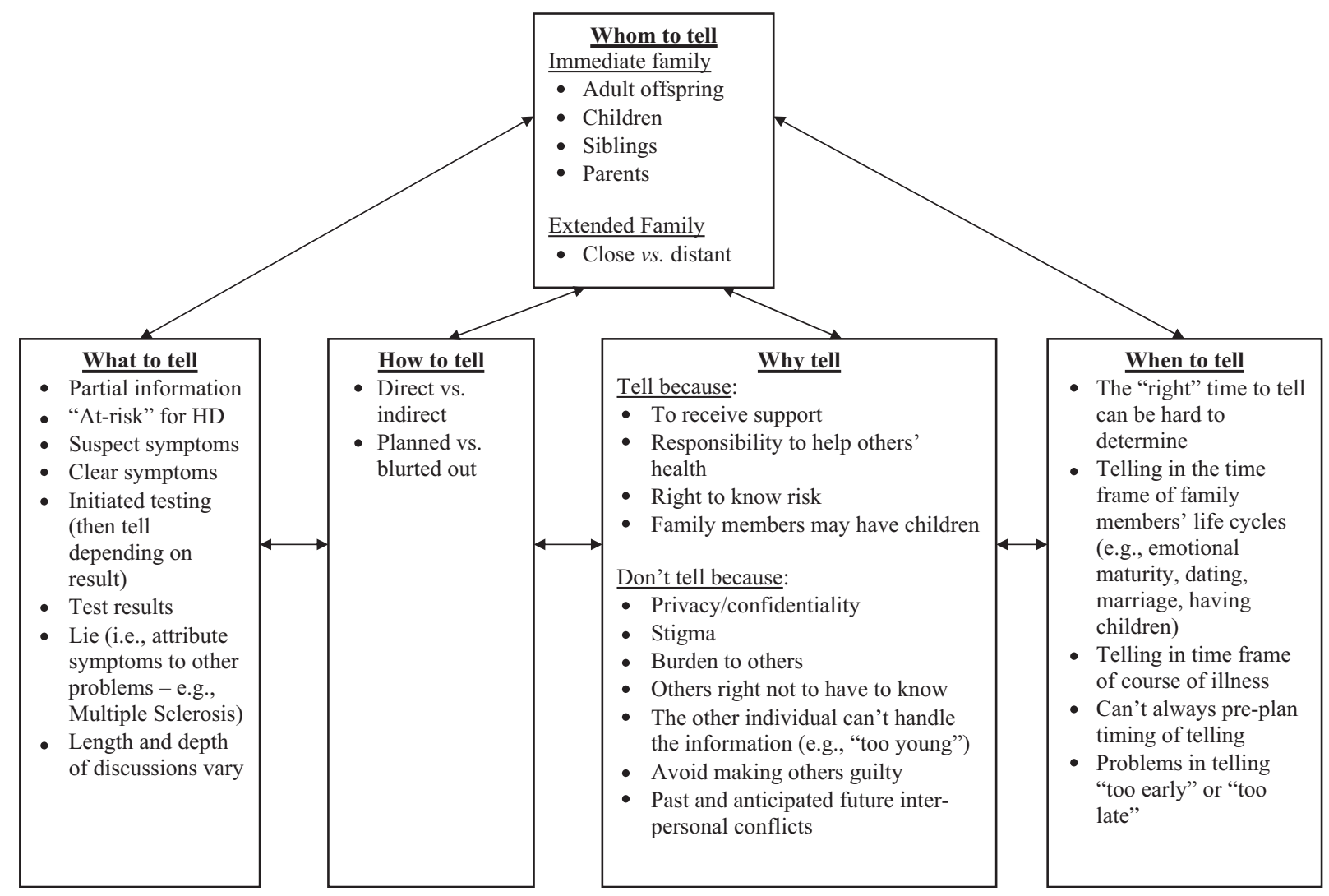

FIG. 1. Model of factors weighed in disclosure decisions.

thing that I want to trouble my mother and my sister's family about? Probably not, unless I was fairly certain." [15:M/Sx/+]). Partial information could frighten others, perhaps unnecessarily.

Coded or only partial information may be divulged. Individuals could disclose that they had initiated the counseling process, and/or that they had undergone the actual test.

I didn't tell anyone in my family except my little sister that I was doing this. She knew I initiated the testing, but she had no idea how far along in the process I was. . . They thought I was still in the counseling session, though I'd had the blood drawn...The night I found out I was gene negative, I. . .told them...I didn't want anyone...watching for signs of how I was doing. I had gotten good at obfuscating things, which I was never good at before: "yeah, things are still in process." [12:F/Asx/-]

Though asymptomatic, she still assumed she might have the mutation, and hence withheld information.

Others revealed only that HD was a possibilityeven if it had in fact been diagnosed - that particular symptoms had developed, but not mentioning a diagnosis per se. Some said "ataxia" that was not specific, for example, rather than use the label "HD." HD was purported to be multiple sclerosis, alcoholism, or "nerves."

Within families, overt deceit can be encouraged and defended. Older family members may dissemble to offspring who were now in their 40 s, and still did not know.

My aunt and uncle lied to their offspringmy cousins-and said my mother has MS. My cousins have to know something's wrong with her. My aunt was adamant: "do not tell!" I have no reason to tell her children. We're not that close. It's her business. [8:F/Asx/NT]

This interviewee felt justified in her reticence, since her relationship with her cousins was not close enough, she felt, to obligate divulgence. Yet silence can in fact generate lies, since family members may ask questions.

My daughter said to me, "Where are you going?" I said, "The hospital." They know I come here. They think it's for cancer: "I'm going on a test study for people who are caregivers"...there is always that little white lie. [8:F/Asx/NT] 
Untested, she did not want to disclose even her risk to her daughter. As she suggested, too, lies vary in size and degree, with different moral implications-a "little" vs. "a lot", "white" vs. other. "White" suggests innocence and innocuousness of a lie-ostensibly making it less ethically problematic. In her mind, this concealment was not as egregious as some othersfor example, denying the presence of a known disease.

Though at first, many tried to hide evidence of the disease, at a certain point, visible symptoms preclude concealment. ("I try and minimize my movements so people won't actually notice. So I can try and walk like normal people..." [2:M/Sx/NT]) The view of oneself as "normal" suggests how HD is seen as "abnormal" and is thus stigmatized, motivating caution in disclosures.

\section{How to Tell}

How to disclose also proved difficult. Individuals had to gauge how to "prepare the ground" in advance, over time, to minimize responses of shock-whether the information is that one is at-risk for HD, or has been found to have the mutation.

What I've really learned is: it's how you tell...If I find out horrifying news, and run home, and just blurt it out, and don't prepare the ground-I've attacked people with it. The way people talk to each other about this stuff can really make a difference! [12:F/Asx/-]

Disclosure can thus occur as a process over time, and be gradual or abrupt.

Disclosures also varied in the degree to which they entail discussion of relevant additional information. Discussion can be threatening and ultimately overwhelming, and hence eschewed. Siblings, for example, also at risk, may not want, or be able to, discuss it.

There really isn't much left to say, other than I got tested, and was positive. . there wasn't a lot of back and forth about them getting tested or not. [4:M/Asx/+]

His perception that there "isn't much left to say" suggested, too, the possibility of mutual avoidance of further discussion (i.e., between tellers and listeners).

In part, families vary a priori in styles and norms of communications (e.g., "My family does not communicate well about their emotions. They really just keep things completely to themselves. We're not ... a a very talkative family." [4:M/Asx/+]).

Since explicit conversation may be too threatening, indirect or implicit rather than explicit communication, or nervous humor can prevail.
My sister and I never spoke about it, or about her getting it...We probably will have that conversation one day. But I guess we speak about it in conversation without speaking about it. She might even say, 'You know, we can get that disease one day.' I'll say, "I know." But we don't get into details. We'll just talk about what our brother's doing...and we laugh about some of the crazy things he does...Not, "What would you do if you got it,' or 'Are you going to get tested?' [3:M/Asx/NT]

They could, but do not, discuss a wide range of "details". He felt they should have more of a conversation, but they did not do so, since the conversation was personally too threatening. Given this tension, he saw them as delaying the conversation, rather than permanently prohibiting it. Still, they communicate indirectly (e.g., about mutual anxiety or unease).

As above, such reticence can build on longstanding histories of silence-over multiple generations-arising in part from not only general family communication styles, but expressed minimization or denial of this particular problem.

We didn't have those conversations growing up. My father never talked about it. He'd act like nothing was wrong, like my mother was Ok...he never wanted to talk about it. [14:M/Asx/+]

This interviewee now had to make disclosure decisions, having had denial and deceit as his only models. How one's parents discuss HD can shape how one later talks about it to one's own children and siblings.

Alternatively, disclosure may transpire immediately and unhesitatingly because it is fully expected within the culture and implicit norms of a family. Family members may simply expect to be told. A Latin American man said,

We like telling people, especially in my country, because one day [my father] will be dead, and why was he dead? Why didn't they tell us? The whole family knows. They are totally aware. They have to be. We have to be totally straight up honest...or else they will never forgive us. [17:M/Asx/NT]

One could later be blamed for non-disclosure. Of note, he was asymptomatic and untested-states that may be less difficult to disclose than having the mutation.

Particular questions arise concerning what and how to tell children, since they often have less capacity to understand or cope. Such disclosures and 
discussions can vary widely in their components, and be indirect or even non-verbal.

My mother said, 'The neurologist said: at breakfast one morning, put this booklet about HD on the table. If no one asks about it, don't worry about it.' [5:M/Asx/+]

Thus, the existence of the disease can be broached, but not the fact that family members may have it.

Especially with children, partial and incomplete information may also be given piecemeal over several years, generating misunderstandings. ("The information just leaked out in bits and pieces over a number of years...You hear people saying things, you get the wrong idea." [5:M/Asx/+]). Incomplete information can thus foster misunderstandings about what was not being said. An informed individual may tell other family members, constituting "secondary disclosure," though the original discloser may object, creating tensions. ("My mother told me she was going to tell my older brother, but not my younger brother and sister until they were older" [7:F/Asx/+]). Hence, an individual's diagnosis may be disclosed not by that individual, but by another, with or without the diagnosed individual's permission.

Yet given gradations in children's cognitive and emotional maturity, input from HCWs can perhaps particularly help parents with disclosures.

My mother should not have been the one to tell us, but a therapist, a social worker. Somebody should have sat down with my parents in the room... We found out in a bad way. We never discussed it together. [5:M/Asx/+]

Disclosures can thus vary in quality, as relatively "bad" or "good" according to several parameters.

\section{Why Tell}

Issues arose concerning why tell or not tell, shaped by who was being told. Generally, similarities and differences arose between types of relationshipsthat is, parents telling offspring, offspring telling parents, and siblings telling each other. Separate, though related reasons to tell or not tell emerged with siblings, parents, children, and extended family (cousins, aunts, and uncles). For many, the very meaning of genetic disease is that other family members are risk, yet the issues involved in disclosure differed somewhat by categories of relationships. Still, certain questions and concerns were shared.

Once symptoms appear, disclosure may become both unavoidable and essential for coping optimally with the illness. As one symptomatic but untested woman said, "I don't really think I can live a normal life if I don't have a few people close to me who know." [19:F/Sx/NT] She felt she had to tell at least some people in order to gain instrumental support for the stresses posed by the illness.

Family members were thought to have the right to know if they were at risk. Specifically, many individuals disclosed because of perceived responsibility to foster the health of family members, enabling these others to pursue appropriate medical evaluation and family planning, if desired. Disclosure thus also occurred to avoid potential further transmission of the mutation. Adult offspring, too, felt that their parents, even if not wanting to find out more about HD and deal with it themselves, had an ethical duty to tell them at some point.

Yet tensions emerged because the information could burden the recipient. These feelings often stemmed from other, prior experiences and interactions, and desires to avoid troubling elderly parents already overwhelmed by the effects of HD. Individuals often feared that parents, if told, could feel guilty about having transmitted the disease. Though such feelings may not be rational, even a parent not at-risk may experience such guilt about not having stopped the potential spread of a spouse's mutation to children. As one man, whose mother had died of HD, said, "It was hard to tell my father, not because of privacy, but because he felt guilty...that he might have passed it on...After my parents had my youngest sister, the doctors told them they shouldn't have any more children" [6:M/Sx/+].

Parents may justify non-disclosure to children based on desires to avoid burdening these offspring. These decisions are difficult, pitting secrecy in the name of protection against risks of further spread of the gene. One woman reported that her parents said,

"We were just protecting you. We didn't want you to deal with it. We had 30 good years before this hit us. Why can't our kids have a childhood? Let's let them enjoy their childhood, and not worry about their health." [8:F/Asx/NT]

Here, too, issues of when to tell emerge.

Some hesitated to disclose information, since to do so can also be painful, and compromise one's confidentiality. To bestow on others trust and knowledge allots them power that they could then use against one. HD risk led many to be cautious in disclosing information more generally.

If you tell someone how you feel, you give them a gift. You're trusting them to be able to respond to your feelings in a helpful way. It's been very useful to me to hide some things. [12:F/Asx/-] 
This knowledge can constitute a "gift" because it affirms trust-closeness and a particular relationship_-and gives others a certain power, since they could spread the knowledge. Yet the disclosure can also strengthen the relationship-demonstrating such trust. People may appreciate being told, since they can also make constructive use of the information (e.g., being able to offer support).

The fact that HD causes psychiatric symptoms also impeded disclosure. Individuals made assessments, too-correctly or not-that family members, because of age and psychological fragility (due in part to possible symptoms), could not handle the information. Differences may be perceived in the emotional vulnerability versus resilience of siblings. Individuals may vary psychologically in their coping styles-for example, taking more emotional versus rational approaches. ("When bad news comes, my mother, sister, and brother...immediately...think of the worst...I am definitely more organized and together" [7:F/Asx/+]). Psychiatric symptoms are also stigmatized, adding to HD being a "big secret in the family."

No one talks about it, or says they're at risk. My sister-in-law and I talk 10 times a day. She said, "It's not cancer-an acceptable diseaseor Parkinson's. Because it affects you mentally" ...my mother. . .embarrasses us, saying dopey things to people...People always look at her as if she's drunk. [8:F/Asx/NT]

Even without symptoms, being at-risk can be too difficult to discuss, in part because psychiatric symptoms can cause discrimination and generate additional fears, representing loss of control, and not generally being fully treatable.

Yet psychiatric symptoms can themselves impede responses to disclosure either directly (through symptoms) or indirectly (through stress that results). HD may adversely affect parents', spouses', siblings', or children's abilities to interact with others. Family members, particularly parents, may be insensitive or not fully supportive. ("I wasn't going to tell my mother, because I didn't feel I would get any support from her. She... is generally not good at understanding." [5:M/Asx/+]) HD can thus pose obstacles to good parenting that compound these difficulties.

Particularly among siblings, strained and estranged relationships can impede disclosure. Though some siblings immediately informed each other, since if one had the gene, others were also at risk, obstacles-related to the nature of the relationship_could impede or prevent these divulgences. Given the anxieties involved, siblings may simply not want to know (e.g., "I asked my brother... "Would you want to know if I'm positive or not?" He said no." [7:F/Asx/+]). An individual could often approach each sibling differently, based partly on perceptions of that sibling's resilience and possible symptoms, or responses to a prior question of whether the sibling would want to know. Family members were felt to have a right not to know if they wished. Avoidance of disclosure can also verge on denial that can potentially hamper treatment.

Even though my older brother lived like he had the disease anyway, he didn't really want to talk or know about it. We tried to get my twin to see a therapist. He went once. [5:M/Asx/+]

Even if both tacitly know their mutual risk, siblings may avoid discussing it prior to disclosure due to the threat of disease. ("My brother just skirted around the issue. I asked direct questions and wouldn't get any answers back." [21:F/Asx/-])

\section{When to Tell}

Decisions of when to disclose were shaped by two sets of time frames - that of the life cycle of the family member who is told, and that of the medical course of the affected members. Within families, concerns about disclosure issues tended to increase at critical junctures in the life cycle of at-risk individuals-at points of marriage, engagement, or having children. When and how disclosures occur can be closely related. Though careful plans may be made concerning disclosure, advanced decisions can be hard to carry out, and the information can instead simply leak or get blurted out ("I didn't tell my mother. Then we ended up having an argument, and I told her, which is exactly what I didn't want to do." [5:M/Asx/+]). Without symptoms, the revelation that one carried the mutation could shock others because the disease was not yet visible.

Decisions of what and when to tell also shaped each other. Some wondered, for example, if they should tell when suspecting symptoms, versus waiting until initiating testing, or obtaining results. Conundrums of when to tell arose particularly with children. Dilemmas of at what age and juncture to disclose a parent's disease are important since when a parent discloses to his or her offspring, the latter is thereby learning of his or her risk status-usually for the first time. Young children may feel overwhelmed by too much information about a parent's disease, but utter silence can cause harm as well.

A few learned about their risk as relatively young children, but varied in how they later viewed their parents' decision to disclose at that point. Certain information about $\mathrm{HD}$ can be helpful, even if frightening. As one man said,

I was ten when I first found out. I was very stressed out about it, very depressed, unable to sleep for a while. It was really tough, hearing 
that I was at risk for the disease. My mother told me that she had children because there might be a cure for the disease eventually. I was actually okay with that... But for a long time it was very tough - the fact that I might get a disease like my mother...Me and my sister were able to understand at ten...My mother first showed symptoms when we were 8 or 9 . My aunt also had HD, and was 15 years older than my mother, so they were able to tell us that 'it's probably going to be like what your aunt has.' [18:M/Sx/+]

He thinks it was appropriate that he was given information when he was.

Looking back on it, it was very right...She just told me about the disease so that I could understand. My pediatrician did the same. He could have told me all these facts about the disease. He told us in a way we could understand at ten: that there is a fifty/fifty chance, so we were able to understand about our own risk, and what to expect with our mother's progression. . [ [18: $\mathbf{M} / \mathbf{S x} /+]$

Here again, who is told shapes what is told: young children can be given age-appropriate information. Ironically, the fact that the disease is genetic, and thus visible in other kin, may make it less abstract and more understandable, even if still frightening.

Still, others felt that they were told too early - that they were too young for the information they were given. A critical distinction emerged, for example, between knowing about the disease in general (and that it affected a parent) versus knowing that one was at risk oneself.

For a 15-year-old girl, that's a lot to put on her shoulders. But my dad thought I was up to the task. He has always confided in me as a friend rather than daughter-things like money worries. I don't think he should have done that at an early age, because I used to worry for him. It made me older than I should have been. . .I grew up very young. [21:F/Asx/-]

She now felt that 15-year-old should not be told. Yet the age at which one is "old enough" may not be clear.

I don't know how one should decide when one is old enough. That's very personal, hard. Everyone's individual. Maybe it's when someone's in a stable, happy point in their life...someone getting ill has to know. That's the cut off point: when they're ill. [21:F/Asx/-]

Criteria thus arose of being stable, "happy," and cognitively and emotionally mature.
Alternatively, some felt that they were told too late. Disclosure may not occur until an offspring's marriage-transpiring only then so that prospective spouses might know before they marry and consider children.

Growing up, I was aware that MS was in the family, but never really thought about it. Then, I got engaged to my husband. My mother said-like she had been keeping a family secret-that it wasn't actually MS, but HD. She wanted to tell me before we got married, because she didn't want my husband to marry into the family when this was there." $[7: \mathbf{F} / \mathbf{A s x} /+]$

This woman was angry at her mother's both nondisclosure and view of the disease as shameful. Similarly, another woman reported that her sister, with 22 and 20 years old sons, said,

"When I know that my oldest is going to get married, I'll tell him." But isn't that too latewaiting until he's engaged...? Now that he's met the woman of his dreams, he's going to hit her with this? That's wrong. [8:F/Asx/NT]

Adult children at risk might not be told by a parent, and they may then have children themselves, not knowing of the risk. In keeping the family's HD secret from children, and then disclosing it "too late," such delay and dissembling may incur later resentment.

Now we find out, when we're 24, that they've been lying to us our whole lives. They knew about this, and didn't do anything. I've been dating my husband since I was 16. So, if she wanted to make sure we didn't get serious, she should have told me way back then, not after we've been dating seven years. [7:F/Asx/+]

Several factors may account for such delays. Some thought that over recent years, attitudes towards HD disclosure have changed. The older generation may have kept HD more of a secret, as it was less understood and perhaps as a result more stigmatized.

The timing of disclosure may be based, too, on parents' perceptions of offsprings' maturity. Hence, not all offspring may be told simultaneously. Disclosures to children may come in waves, since offspring may be of different ages - often spread out over a decade or more. Hence, within a family, some siblings may know while others don't, forcing those who know to maintain secrecy.

\section{Telling Extended Family Members}

Separate though related quandaries emerged of whether and when to contact extended family 
members, including "long-lost relatives" who may unknowingly be at risk. Such contact can constitute the only notification long-lost kin receive that they are at-risk. Yet with extended relatives, rules were unclear, since patterns of relationships are more fluid and less socially prescribed. Some attempted to reach out to somewhat distant relatives, yet decisions of what and how to communicate could be hard, and the ideal tone of such missives difficult to achieve. Such letters can be troubling not only to send but to receive, in part because they are utterly unexpected. ("It came out of nowhere, a surprise. I wasn't expecting anything." [13:M/Asx/-]) Many tested individuals lacked detailed knowledge about extended family members ("My mother had 9 siblings. My grandmother had 10, of which 9 had it. I have second cousins in different places. I don't keep in touch with them. I don't know of any diagnosed. [6:M/Sx/+]). He thus felt justified in not contacting them. Distance can perpetuate further distance, and conversely, closeness can foster added closeness.

Relatives may not be contacted because they're "long-lost," or, even after being contacted, further or reciprocal communication may not occur.

I don't have a deep sense of connection to them. It would be like contacting a near stranger. We're connected in having a family history, but I don't have an emotional connection to them. [13:M/Asx/-]

Individuals may be close biologically, but not socially. Questions surfaced, too, of how to reply to information from a distant family member. Distance may be mutually perceived. ("I might have responded with "I'm sorry," but it was minimal." [13:M/Asx/-]) Other obstacles may block such disclosures as well. As above, family members may object to disclosures to particular relatives, and explicitly tell members not to inform certain relatives. ("My dad's brother called my mother, but didn't want his kids to know. I was not to speak to them about it. .." $[7: \mathbf{F} / \mathbf{A s x} /+])$

Given various obstacles, warnings to long-lost relatives of their HD risk may get ignored-letters are discarded or put away, all but forgotten.

The day I learned about HD in our family, my father gave me a letter from my mother's first cousin in the South saying that someone had HD, and was there anyone else in the family showing signs? This letter had been written years before. It had been in his drawer 3-4 years. My parents had ignored the letter, and not gotten back to them, which I found appalling. "How could you? Someone in our family is reaching out for help!. . .you're not even contacting these people to say: yes, we do have it in our family. You knew this was in the family, and you just chose not to tell us!" I called this cousin that day, got in touch with the son and daughter, and became friends with them. [8:F/Asx/NT]

Thus, disagreements can occur about not only informing non-immediate family members, but responding to the information once received. With distant (vs. close) relatives, the social, and hence ethical bonds were less, leading to less involvement with, and knowledge of, these relatives' reactions and responses.

My cousins have thought about testing... I don't know if they've made much progress. We had never really talked about their issue until after I got my results. . .My cousin thought I had the bigger burden to carry. I'm not going to bother him with my own life... I had a 5050 chance, and they had a $25 \%$ chance... [11:M/Asx/-]

Extended family members may simply not want such communication. Relatives at risk may just refuse to deal with it, and not respond when urged to do so. "I have a cousin. His mother died of it. My sister tried to contact him 3-4 times, but he won't return her calls. He's probably very scared." $[\mathbf{1 8 : M / S x / + ] ~ I n ~}$ part, not to bother contacting such relatives is easier, but such communication can in fact prove helpful.

The type of relationship (e.g., immediate vs. distant family; emotionally close vs. distant) can shape how these factors are balanced as well. Importantly, biological and psychological bonds shaped perceptions of these ethical bonds. Distance (vs. closeness) in the relationship_that is, being extended family members or estranged-reduced the sense of responsibility to aid one another's health.

\section{Testing Family Members}

As seen on Table III, post-disclosure, difficult questions arose, too, of whether to pressure family members-adults or children-to be tested, and if so, to what degree.

For several reasons, some sought to get family members tested-often to gauge a third party's risk. Some wanted a parent tested, for example, so that neither they nor their kids would have to undergo testing themselves. ("I said to my mom, 'I want you to be tested for us."' [8:F/Asx/NT]) Her kids would then not be at risk if her mother were negative. Yet that desire required her to pressure her mother to test. A parent may readily agree, given the trade-off, or feel imposed on. Hence, individuals had to balance their own rights and desires versus their perceived obligations to other family members. Disagreements occurred. 
TABLE III. Issues Involved in Testing Family Members

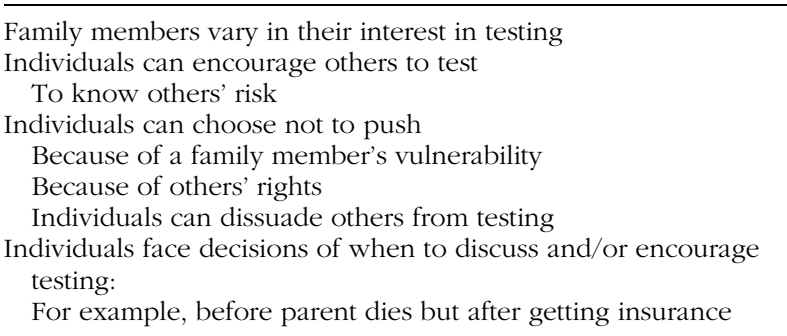

Yet others deferred from pressuring family members-particularly those who show symptomsfrom getting tested. One woman thought her brother had early HD symptoms, but would not cope with the result well. Thus, she did not want him tested.

I think my brother has it. That's why I don't push him anymore to get the test. Huntington's people get a look in their eyes...even when there's no signs or symptoms-a glazy, spaced out look... [21:F/Asx/-]

Others did not want very young or very old certain family members tested, and actively deterred them.

Yet the reasons family members may seek to dissuade each other from being tested may or may not be seen as valid.

My grandmother tells my aunt and uncle they might eventually die-which is true. But she scares them off. My aunt is petrified [by my grandmother] of this whole situation, to where she doesn't want to get a test done. [10:F/Asx/NT]

Within the same family, individual receptivity to the option of testing can vary dramatically, due in part to personalities and perceived repercussions of test results.

Everybody has such different opinions on it. I'm the only one out of 5 in my family that will be tested. The rest refuse, except my sister who...feels she's showing signs. [8:F/Asx/NT]

But this interviewee herself had not yet been tested.

Strong feelings emerged about not only whether family members should be tested, but when. Some encouraged family members to get testing at particular times-seeing benefits at particular junctures. One man told his brother to test before their father died of $\mathrm{HD}$, in order to arrange for insurance.

You should get your insurance straightened out soon. When he died, it got more difficult.
Then, if they ask you, "Are your parents alive? What did they die of?" You have to lie, and potentially they could invalidate your insurance. [13:M/Asx/-]

Yet despite possible symptoms, some family members refused to seek evaluation.

I said at to my sister-in-law, "Do you think my brother could be showing any signs? He has anxiety, depression." She said, "He might be, but he'll never come in." [8:F/Asx/NT]

\section{Others' Input Into Disclosure Decisions}

As mentioned earlier, dilemmas arose of how to negotiate disagreements about disclosure within a family (e.g., of whether to tell cousins, if their parents do not want them to know). Even spouses could vehemently disagree about disclosures ("I try not to bring it up with my husband. It's my only argument with him." [1:F/Sx/NT]). In disagreements about disclosures, generally, closer relatives' assessments prevailed. More distant relatives deferred, since less biological closeness was felt to lessen ethical obligations.

HCWs have potential input in disclosure decisions, yet their roles were rarely, if ever, mentioned. At times, genetic counseling was seen as falling short because it did not prepare individuals to deal with disclosure issues. ("I didn't know who to tell, or what to say. I wasn't prepared for it." [8:M/Asx/+])

\section{DISCUSSION}

These data illustrate the complexities involved in disclosures by individuals who have or are at risk for HD to their family members. Tensions arose related to ethical, social and psychological concerns. Importantly, these data revealed issues not examined previously concerning what and how individuals disclose, whether disclosures occurred to extended family members, and whether family members were tested post-disclosure. Issues concerning disclosure to close more than to distant relatives have been explored with other disorders (e.g., hereditary breast and ovarian cancer [Hughes et al., 2002; WagnerCostalas et al., 2003]), but not heretofore with HD. Some individuals, informed that they were at risk for $\mathrm{HD}$, pursued genetic testing, and were glad that they had been told, enabling them to make informed decisions about their lives. Yet in other instances, the information was disclosed, but then essentially ignored. Often, due to the potential stigma, only partial or indirect information was provided. Disclosure decisions were based on several factors, including perceptions of others' ability to handle the information, intra-familial norms of communication, and one's own comfort with the results. While 
advanced plans for disclosure might be made and carried out, emotional factors could make disclosure decisions not always rational and predictable. At times, the information got blurted out.

Importantly, while HCWs may encourage individuals at-risk for HD to disclose that fact to family members who are also at risk, such disclosure may also then entail divulgence of one's own diagnosis. It is very difficult to disclose that one is at-risk or has initiated testing without also then divulging the test result-which, if positive, constitutes one's diagnosis. Disclosure may prompt questions or obligations concerning the discloser's own test results. Yet such disclosure of diagnosis can be difficult, depending on previous family communication style and knowledge of the disease. This information can be stigmatized, and change others' perceptions of one, even in one's own family.

Other obstacles to disclosure-even of being atrisk-may exist as well. These disclosure decisions can be part of dynamic processes. Here, distance and closeness can also each be self-perpetuating. Between people, non-disclosure, too, can be mutually reinforced-constituting a policy of "don't ask, don't tell." Even being asymptomatic, if untested, is hard to disclose and can lead to lies. Individuals who know they do not have the mutation may face less difficulties, but not entirely if their disclosure involves informing others that these others are in fact at risk. Patterns of disclosure or non-disclosure can also extend over more than one generation, possibly becoming self-perpetuating. Importantly, many of these individuals had strong feelings and attitudes toward other family members' both disclosure decisions and views of the disease.

Our findings both resembled, and differed from, those of prior studies. Forrest et al. [2003] found that in Northeast Scotland, the right time to tell children was usually when they were potential parents, that is, about to be married. In our sample, parents often faced these issues earlier. Perhaps in part, in an urban US setting, offspring may have children later, if at all, as opposed to in Northeast Scotland. Thus, even between Western countries, both similarities and differences may arise. Systems of health insurance vary between countries in ways that may affect disclosure decisions. Yet such international differences have received little attention in studies of psychosocial aspects of HD. We found, too, that the timing of disclosure occurred not simply based on "prevarication vs. pragmatism" as in this prior research, but that information sometimes got "blurted out," for example, in arguments. Forrest et al. found as well that individuals felt that some relatives didn't 'need' to be told, while in our data, interviewees felt that some relatives also did not 'want' to be told-because of perceptions that these others were feeling too fragile due to symptoms or risk of HD. These prior investigators found that women often served as gatekeepers of genetic knowledge more than did men. We did not find that to be as much the case-perhaps in part since they interviewed 50\% more women than men, and included breast cancer (which affects primarily women) as well as HD, while we examined only HD. Hamilton et al. [2005] found that participants confronting hereditary breast and ovarian cancer, but not HD, tried to affect family members' own testing decisions. In our data, these issues arose among participants facing HD as well. Hamilton et al. did not discuss disclosures to adult children. The present data suggest, too, that one's own specific status (i.e., not tested, mutation carrier, or non-carrier; and symptomatic or asymptomatic) may affect some disclosure decisions. Past studies have not assessed these factors, but future research should do so.

Similar to the rational choice Health Belief Model, which addresses whether individuals decide to engage in health behaviors [Rosenstock et al., 1988], we found that individuals weighed pros and cons of whether to disclose, but that complex issues and factors also arose concerning decisions of what, how, and to whom, to disclose. Factors were not always rational (i.e., the information sometimes got "blurted out"). These data illustrate, too, Goffman's theories of how individuals seek to "manage" stigmatized information about themselves. Yet here, these desires can conflict with ethical notions of responsibilities towards one's kin; and of truthtelling. Sissela Bok in Lying: Moral Choice in Public and Private Life [Bok, 1999] held that people should never lie. In contrast, David Nyberg in The Varnished Truth [Nyberg, 1980], asked, "what's so good about telling the truth all the time?" and argued that telling lies is an intrinsic and necessary part of human life. Desires to conceal can clash with perceived needs to tell the truth. These conflicts then often get decided based on various other factors (e.g., degrees of closeness, and age of family members).

Future research with larger cohorts can assess these issues, and the roles of various factors (e.g., family background vs. innate psychological traits) further quantitatively. Future studies can assess, too, the effects of when and how one is informed on how one subsequently decides whether, when and how to approach dilemmas concerning testing, reproductive options [Klitzman et al., 2007a,b], and disclosures to others. Relatives who were disclosed to in ways that they felt were adequate and appropriate may make more optimal decisions about whether to pursue testing. Alternatively, those who are disclosed to in ways that they feel are inadequate or inappropriate may delay addressing their HD risk in their own lives. Future studies can explore such hypotheses, and assess views and ranges of definitions of adequate versus inadequate and appropriate versus inappropriate disclosures (e.g., in terms of timing, quantity and quality of information, suppor- 
tiveness, and provision of sufficient information). HCWs may recommend generally that a patient, if he or she can handle it, inform relatives that he or she will be receiving test results, and that these relatives should ask the patient if they want to know the results. This procedure allows these relatives to choose if and when to receive such information. Yet how patients and their relatives respond to such suggestions, and why, remain uninvestigated.

Our data highlight the need, too, for future research to be as sensitive as possible to differences between varying genetic disorders due to particular features of each disease (i.e., penetrance, treatability, means of prevention, and presence of psychiatric symptoms). Disclosures concerning HD may prove more difficult than for many other disorders because of not only being autosomal dominant and highly penetrant, but also causing psychiatric symptoms that can lead to stigma and discrimination. Issues of disclosure to distant relatives take on more importance than with other diseases that pose less, if any, medical risk to extended family members. Given its penetrance, having an HD mutation may have more powerful implications for extended family members than certain other genetic diseases that are recessive and less penetrant.

In these data, the questions of number of repeats and indeterminate ranges did not come up as major issues. Rather, most individuals who tested positive took the positive result in and of itself as the significant fact, and assumed that they were "mutationpositive", in part because it appeared easier to live with this certainty, even if it might ultimately prove incorrect, than with the alternative of high ambiguity and uncertainty. We will be exploring these issues further in future analyses and research.

These participants discussed insurance concerns, but generally not in the context of disclosures to family members. When telling siblings or offspring, these participants were generally more concerned about the implications of the information for their own health and well-being and that of these family members and the latter's offspring. The fact that these family members may encounter difficulty getting insurance appeared to be secondary to the potential life and death issues these family members now faced. Fears of discrimination, including potential threats to insurance, shaped disclosure decisions in social settings outside of families-for example, with coworkers, bosses, friends, dates, and HCWs-in ways that we are currently exploring further.

These data have important implications for genetic counselors (GCs) and other HCWs. Interviewees said HCWs rarely, if ever, discussed with them these issues of disclosure, especially concerning extended family members. Individuals at risk for HD thus wrestle with these complex and nuanced issues without professional guidance. Yet GCs and HCWs can potentially be very beneficial in helping at-risk individuals to consider these issues in advance. Problems arose, for example, concerning secondary disclosure: one family member who was told then wanting to disclose that information to a third member. A HCW can help at-risk individuals anticipate these possibilities before they disclose to family members. Individuals can potentially state to these members that the information can or cannot be shared with others. Such a request may not be honored, but could at least be articulated. Questions appeared as to not only whether these issues should be addressed in genetic counseling sessions, but how. Counselors may ask if disclosure occurred, but what communication exactly transpired is important - what the client disclosed or anticipates disclosing (i.e., partial vs. complete information). Counselors should also address obstacles to communicating information to extended relatives who might benefit from the knowledge. Individuals may feel reluctant to communicate to extended or estranged family members in part because of inertia, due to not having been in contact. But such information may indeed be welcome. These data suggest that these issues are rarely adequately addressed in pre-test counseling sessions, highlighting the need for HCWs to discuss these issues more with individuals who are considering genetic testing-that is, to begin to consider in advance whether, what, how, and when they should disclose results to family members. HCWs need to realize, too, the extent to which these decisions are multifaceted-involving choices not only concerning whether to tell or not, but what, when, how and to whom to disclose. Many of these individuals would have appreciated more guidance about disclosure decisions to immediate family members, too. At-risk individuals would benefit from enhanced education and guidance concerning these issues. At the same time, a HCW may push a patient to disclose to others the fact that these others are at risk for HD, but that disclosure may entail difficult divulgence of the individual's own diagnosis, too. Further research can explore whether, when, how, and how often HCWs discuss these issues with individuals considering undergoing testing.

Professional training needs to make HCWs more aware of the difficulties of these issues, particularly when familial relationships may be strained-in part because of HD in the family, and the stresses that can result. Family therapists have developed effective means of addressing family disagreements [Minuchin et al., 1996; Minuchin and Nichols, 1998] that might prove beneficial to clinicians involved with genetic testing.

These data also described journeys that at-risk individuals underwent before entering a GC's office. They may be at risk, but not learn of that fact for years, even as adults. Or they may receive the information indirectly, incompletely, or belatedly. To understand 
these potential obstacles is vital to ensuring that those who might benefit from genetic counseling and other medical services are made aware of their risk as appropriately as possible.

This study has several potential limitations. The sample size may be small compared to some other quantitative research, but is sufficient for a qualitative study of this kind, to elucidate important themes that emerge. We are unable to test statistically relationships between gender, ethnicity, socioeconomic status, and testing, and symptom status. However, overall, these data reveal several suggestive and important themes that can be pursued further in future research with larger samples. We interviewed participants at one point in time only, but they described their past as well as present history of HDrelated experiences. These individuals are involved with a tertiary care center, yet provided key insights into responses toward HD by parents, siblings, and extended relatives elsewhere as well. We have a relatively high percentage of those who actually tested, because we sought specifically to sample this category, along with others. Yet this sample thus provides valuable insights into how individuals with a range of risk statuses view and approach these issues.

Given the ethical and psychological complexities of these issues, the development and promulgation of enhanced guidelines concerning these activities, based in part on data such as these, may help both HCWs and at-risk individuals.

\section{ACKNOWLEDGMENTS}

The authors would like to thank Kristin Skrabut, Renée C. Fox, Mary DuVernay, James Zvokel, Antonius Wiriadjaja, Carol Moskowitz, and Paula Wasserman for their assistance with this manuscript. Funding for this research was provided through grant 5-R01-HG002431-01 from the National Human Genome Research Institute.

\section{REFERENCES}

Ayme S, Macquart-Moulin G, Julian-Reynier C, Chabal F, Giraud F. 1993. Diffusion of information about genetic risk within families. Neuromuscul Disord 3:511-514.

Bok S. 1999. Lying: Moral choice in public and private life. New York: Vintage Books

Deftos LJ. 1998. The evolving duty to disclose the presence of genetic disease to relatives. Acad Med 73:962-968.

Dudok DeWit AC, Meijers-Heijboer EJ, Tibben A, Frets PG, Klijn JGM, Devilee P, Niermeijer MF, 1994. Effect on a Dutch family of predictive DNA-testing for hereditary breast and ovarian cancer. Lancet 344:8916.

Everett M. 2004. Can you keep a (genetic) secret? The genetic privacy movement. J Genet Couns 13:273-291.

Fanos JH, Johnson JP. 1995. Barriers to carrier testing for adult cystic fibrosis sibs: The importance of not knowing. Am J Med Genet 59:85-91.

Forrest K, Simpson SA, Wilson BJ, van Teijlingnen ER, McKee L, Haites N. 2003. To tell or not to tell: Barriers and facilitators in family communication about genetic risk. Clin Genet 64:317326.

Forrest Keenan K, Simpson SA, Wilson BJ, Van Teijlingen ER, McKee L, Haites N, Matthews E, 2005. "It's their blood not mine": Who's responsible for (not) telling relatives about genetic risk. Health Risk Soc 7:209-226.

Geertz C. 1973. Interpretation of Cultures: Selected Essays. New York: Basic Books.

Gifford SM. 1986. The meanings of lumps: A case study of the ambiguities of risk. In: Janes C, Stall R, Gifford SM, editors. Anthropology and Epidemiology: Interdisciplinary Approach to the Study of Health and Disease (Culture, Illness and Healing). Boston: Reidel Publishing Co. p 213-246.

Goffman E. 1963. Stigma: Notes on the Management of Spoiled Identity. New York: Simon and Schuster.

Green J, Richards M, Murton F, Statham H, Hallowell N. 1997. Family communication and genetic counseling: The case of hereditary breast and ovarian cancer. J Genet Couns 6:45-60.

Hamilton RJ, Bowers BJ, Williams JK. 2005. Disclosing genetic test results to family members. J Nurs Scholarsh 37:18-24.

Hughes C, Lerman C, Schwartz M, Peshkin BN, Wenzel L, Narod S, Corio C, Tercyak KP, Hanna D, Isaacs C, Main D. 2002. All in the family: Evaluation process and content of sisters' communication about BRCA1 BRCA2 genetic test results. Am J Med Genet 107:143-150.

Julian-Reynier C, Eisinger F, Chabal F, Lasset C, Nogues C, Stoppa-Lyonnet D, Vennin P, Sobol H. 2000. Disclosure to the family of breast/ovarian cancer genetic test results: Patient's willingness and associated factors. Am J Med Genet 94: $13-18$.

Klitzman R. 1997. Being Positive: The Lives of Men and Women With HIV. Chicago: Ivan R. Dee, Inc.

Klitzman R, Bayer R. 2003. Mortal Secrets: Truth and Lies in the Age of AIDS. Baltimore: Johns Hopkins University Press.

Klitzman R, Thorne D, Williamson J, Chung W, Marder K. 2007 a. Decision-making about reproductive choices among individuals at-risk for Huntington's disease. J Genet Couns (in press).

Klitzman R, Thorne D, Williamson J, Marder K. 2007b. The roles of family members, health care workers and others in decisionmaking processes about genetic testing among individuals at risk for Huntington's disease. Genet Med (in press).

Lerman C, Peshkin BN, Hughes C, Isaacs C. 1998. Family disclosure in genetic testing for cancer susceptibility: Determinants and consequences. J Health Care Law Policy 1:353-372.

Minuchin S, Nichols MP. 1998. Structural family therapy. In Dattilio FM, editor. Case Studies in Couple and Family Therapy: Systemic and Cognitive Perspectives. New York, NY: Guilford Press. p 108-131.

Minuchin S, Lee WY, Simon GM. 1996. Masters of Family Therapy: Journeys of Growth and Transformation. Oxford, England: John Wiley \& Sons, Inc.

Nyberg D. 1980. The Varnished Truth. Chicago: University of Chicago Press.

Parsons T. 1951. Illness and the role of the physician: A sociological perspective. Am J Orthopsychiatry 21:452-460.

Peterson SK. 2005. The role of the family in genetic testing: Theoretical perspectives, current knowledge, and future directions. Health Educ Behav 32:627-639.

Peterson SK, Watts BG, Koehly LM, Vernon SW, Baile WF, Kohlmann WK, Gritz ER. 2003. How families communicate about HNPCC genetic testing: Findings from a qualitative study. Am J Med Genet Part C Semin Med Genet 119C:78-86.

Plantinga L, Natowicz M, Kass N, Chandros S, Gostin L, Faden R. 2003. Disclosures, confidentiality, and families: Experiences and attitudes of those with genetic versus nongenetic medical conditions. Am J Med Genet Part C Semin Med Genet 119C:51-59.

Rosenstock IM, Strecher VJ, Becker MH. 1988. Social learning theory and the Health Belief Model. Health Educ Q 15:175183 . 
Sobel SK, Cowan DB. 2000. Impact of genetic testing for Huntington disease on the family system. Am J Med Genet 90:49-59.

Sorenson JR, Wertz DC. 1986. Couple agreement before and after genetic counseling. Am J Med Genet 25:549-555.

Sorenson JR, Cheuvront B, Brunin A, Talton S, DeVellis B, Koch G, Callanan N, Fernand G. 1996. Proband and parent assistance in identifying relatives for Cystic Fibrosis carrier testing. Am J Med Genet 63:419-425.

Sorenson JR, Cheuvront B, DeVellis B, Callanan N, Silverman L, Koch G, Sharp T, Fernand G. 1997. Acceptance of home and clinic-based Cystic Fibrosis carrier education and testing by first, second, and third degree relatives of Cystic Fibrosis patients. Am J Med Genet 70:121-129.

Sorenson JR, Jennings-Grant T, Newman J. 2003. Communication about carrier testing within hemophilia A families. Am J Med Genet Part C Semin Med Genet 119C:3-10.

Strauss A, Corbin J. 1990. Basics of Qualitative ResearchTechniques and Procedures for Developing Grounded Theory. Newbury Park: Sage Publications.
Suslak L, Price DM, Desposito F. 1985. Transmitting balanced translocation information within families: A follow-up study. Am J Med Genet 20:227-232.

Tercyak KP, Hughes C, Main D, Snyder C, Lynch JF, Lynch HT, Lerman C. 2001. Parental communication of BRCA1/2 genetic test results to children. Patient Educ Couns 42:213-224.

Tercyak KP, Peshkin BN, DeMarco TA, Brogan BM, Lerman C. 2002. Parent-child factors and their effect on communicating BRCA 1/2 test results to children. Patient Educ Couns 47:145153.

Wagner-Costalas J, Itzen M, Malick J, Babb JS, Bove B, Godwin AK, Daly MB. 2003. Communication of BRCA1 and BRCA2 results to at risk relatives: A cancer risk assessment program's experience. Am J Med Genet Part C Semin Med Genet 119C: $11-18$.

Wilson BJ, Forrest K, van Teijingen ER, Mckee L, Haites N, Matthews E, Simpson SA. 2004. Family communication about genetic risk: The little that is known. Community Genet 7: $15-24$ 